\title{
La fábrica de embutidos de Segovia Diagramas y matbuildings
}

Palabras Clave: Fábrica de embutidos, matbuilding, organicismo, procesos aditivos, Inza, arquitectura industrial.

La fábrica de embutidos "El Acueducto" es uno de los edificios organicistas más perturbadores y enigmáticos del organicismo madrileño y además casi un caso aislado, pues los arquitectos de esa corriente apenas trabajaron la tipología fabril.

Realizada por el arquitecto Curro Inza, es un edificio de dificil explicación y desconcertante en su forma ¿Por qué hizo esta fábrica tan inexplicable? ¿Qué claves esconde este proyecto? ¿Cómo llego a ese resultado final? Este texto explica cómo dentro de la arquitectura del autor, el de Segovia es el final de una serie y el mejor ejemplo de los proyectos "aditivos" de Inza, pudiendo ser calificado como un matbuilding. El acceso por vez primera vez al archivo personal del arquitecto ha permitido disponer de un material inédito hasta ahora, pudiendo mostrar cuál fue el proceso de gestión y encargo de la fábrica, y las distintas versiones (jamás publicadas) que realizó el autor hasta llegar al resultado final construido. Es BIC desde 2013.

\section{Introducción}

- mulación del salto al vacío...máximo esplendor en la célebre promoción del 59, Fernando Higueras, Curro Inza, Mangada, Peña Ganchegui,...la fábrica de chorizos de Curro Inza, impar pieza de arquitectura, al tiempo un tanto demencial". (Fullaondo 1973)

La fábrica de embutidos "El Acueducto"1 en Segovia (1963-1966) es un edificio dificil de analizar, perturbador en su forma, pero que nos incita a intentar desentrañarlo y entenderlo: ¿Por qué hizo esta fábrica tan inexplicable? ¿Qué claves esconde este proyecto?... Múltiples preguntas por resolver en uno de los edificios más complejos y enigmáticos (¿quizás el más complejo y enigmático?) del organicismo madrileño. Como otros proyectos del autor, el de Segovia queda por explicar.

Proyectos previos y referencias señaladas

No será hasta 1974 cuando Alison Smithson acuñe el término de Mat-building (Edificios estera o alfombra) ${ }^{2}$ para nombrar a los edificios de crecimiento celular a través de la repetición de un módulo y de extensión predominantemente horizontal. Sin em-bargo, en lo que se refiere a la arquitectura contemporánea española, la gestación de esa tipología había comenzado casi veinte años antes en 1956.

Doctor arquitecto $y$ Profesor asociado de proyectos en la Escuela de Arquitectura de Alcalá de Henares
Dentro de ese periodo queda inscrita la carrera completa de Curro Inza, así como algunos de sus proyectos que quedarán marcados por los crecimientos celulares como mecanismo proyectual. Unos proyectos que mantendrán un fructífero diálogo tanto con ejemplos españoles como con internacionales, predominantemente europeos. ${ }^{3}$

Inza utilizó desde el comienzo de su carrera el crecimiento como herramienta proyectual para abandonarlo una vez terminada la fábrica de Segovia.

Este itinerario pasa por algunos proyectos como el Anteproyecto de un comedor en el camping de La Mesquida o su proyecto fin de carrera.

La Mesquida (1958), primer ejemplo celular, procede claramente del proyecto del Pabellón de la Exposición Universal de Bruselas de Corrales y Molezún. Inza conocía este proyecto pues se publicaron todas las fases del mismo: las propuestas del concurso se habian publicado en julio de 1956; el proyecto de ejecución en agosto de 1957 y la obra construida en junio y agosto de 1958 por referirnos sólo a la revista Arquitectura (que era la de mayor difusión en la Escuela de Arquitectura) y esto sin mencionar las múltiples publicaciones en revistas internacionales. ${ }^{4}$

El segundo proyecto celular de Inza es su Proyecto Fin de Carrera (1959). Mientras lo dibuja, se celebrará en Oterloo el primer congreso CIAM plenamente controlado por los miembros del Team X (Cortés 1999) y alli se presentan algunas de las propuestas celulares más relevantes del momento y que mayor influencia tendrán en años 

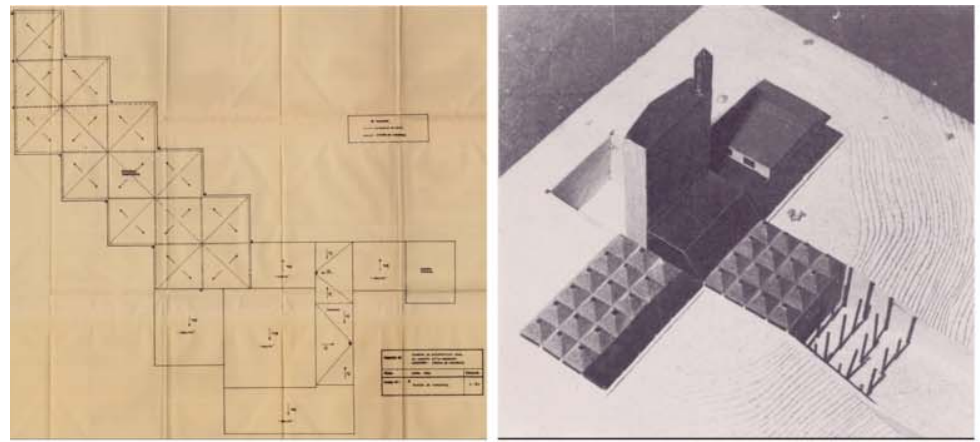

La Mesquida, el proyecto fin de carrera $y$ Casa en Somosaguas. Fuente: Archivo Inza proyecto a las autoridades. Fuente: Archivo Inza
Inza presentando el venideros. ${ }^{5}$ Kahn presentó en el congreso los Laboratorios Richards (Filadelfia.195761), una obra que hablaba tanto de las células como de los espacios intercelulares. ${ }^{6} \mathrm{~A}$ su vez, Aldo van Eyck presentó el Orfanato en Amsterdam proyectado en 1955 y construido en el periodo 1956-60 (Inza publicará esta obra recién terminada su construcción en 1961). ${ }^{7}$ Kahn y el Team $\mathrm{X}$ estaban trabajando en asuntos similares. (Mirado desde este punto de vista el PFC de Inza es una constatación de sus contemporáneos intereses. En él se vislumbran ecos de Trenton y de Amsterdam).

El final del camino aditivo en Inza es Segovia. (Prueba de ello es que cuando Inza vuelva a trabajar con células lo hará desconfigurando el módulo estructural como se aprecia en el chalet en Somosaguas, Madrid, 19658 dónde intentará trabajar, casi de forma kahniana, con el espacio que se produce "entre células". Un sistema que abandonará rápidamente).

En estos proyectos de crecimiento adquieren gran importancia la cubierta y la estructura, pasando a un segundo plano los cerramientos. Toda esta serie de proyectos aditivos terminará en la Fábrica de embutidos de Segovia (1963-66).

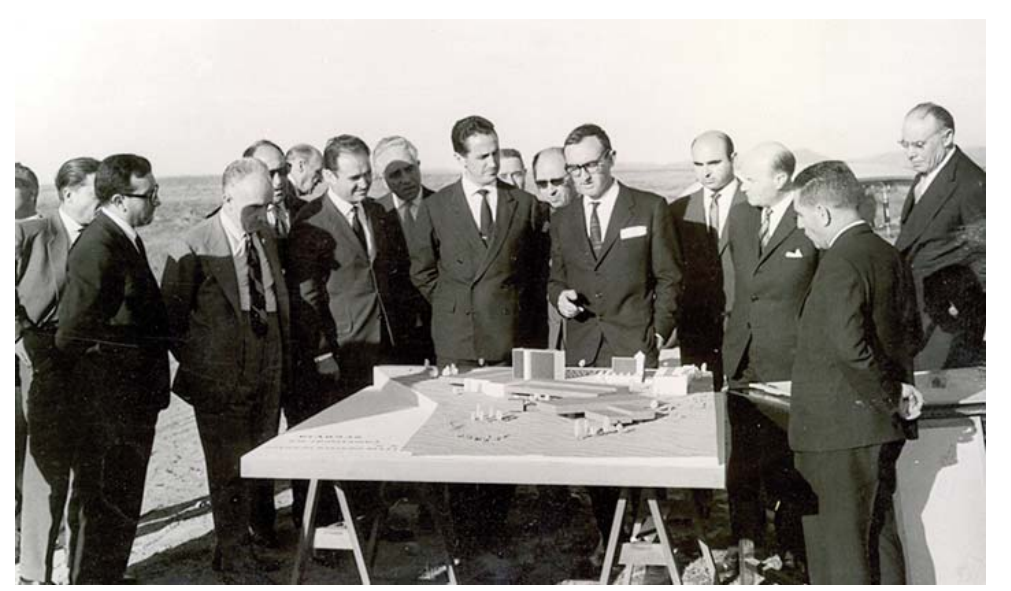

En este sentido la fábrica de embutidos se puede entender como el final de una serie, el más complejo de los proyectos "aditivos" del autor y puede ser calificada como un matbuilding. Mirarlo así, desde el punto organizativo y compositivo, quizás arroje algo de luz sobre un proyecto aún por explicar.

Sin embargo hasta ahora sobre esta fábrica (que junto a las Tapicerías Gancedo y el Café Gijón es el proyecto más conocido y publicado del autor, y el de mayor envergadura de sus obras construidas) se han vertido opiniones poco incisivas en lo proyectual y en lo compositivo. Hasta hoy poco se ha escrito sobre este edificio y a esta fábrica se le supone, como a otras obras de su autor, un enigmático talento. Los autores que se han ocupado de este edificio (casi todos ellos historiadores) han destacado de él mediante brevísimas descripciones dos aspectos, por una parte su imagen y por otra su material de construcción.

En cuanto a su imagen diversos autores han señalado su marcado carácter expresionista ${ }^{9}$ y han intentado establecer parecidos (más como especulaciones personales que como demostraciones proyectuales) con edificios que les resultan similares como los del expresionismo alemán de principio de siglo, los de Poelzig o los de Steiner. 10

Otros arquitectos la han explicado desde el material al compararla con el expresionismo holandés 11 y definirla como "atlántida de ladrillo" (Tena 1999) o bien al resaltar el uso de un material "único y vulgar (la rasilla de ladrillo)” (Ruiz Cabrero 2001:48).

\section{Antecedentes: el encargo de la fábrica}

Los antecedentes de esta fábrica en el trabajo del autor son unos pocos proyectos dibujados, una casa de El Paular y el café Gijón, pues poco más había construido y proyectado Inza hasta el momento de enfrentarse al proyecto que a la postre marcará su carrera. 
El de Segovia se puede considerar el primer trabajo industrial del autor, pues aunque anteriormente había realizado algunos proyectos de arquitectura industrial, todos ellos eran pequeñas naves de dos o tres plantas con estructura de hormigón y en cualquier caso de orden menor. ${ }^{12}$

Existen dos fases construidas de la fábrica: la primera de 1963-66 (que es la más conocida y de la que se ocupa este texto) y la segunda fase que es la ampliación de 1972.

La ampliación la realiza Inza desde la distancia, pues ya se encuentra viviendo en Pamplona. La ampliación no está protegida, no sigue las pautas de la primera fase y carece de interés arquitectónico.

Los dueños, los hermanos Postigo, eran unos importantes industriales de la zona que en 1962 le encargaron a Heliodoro Dols una fábrica de embutidos en las afueras de Segovia, concretamente en la carretera de San Rafael. Dols, amigo y compañero de promoción de Inza, le llamó para hacer juntos el proyecto pero finalmente únicamente participó en el anteproyecto que realizaron a principios de 1963, puesto que Dols abandonó el encargo y se trasladó a Zaragoza para realizar, por encargo de Escrivá de Balaguer, el Santuario de Torreciudad en el Pirineo oscense. ${ }^{13}$ Por tanto no participó en las múltiples versiones que Inza proyectó después, ni tampoco en la dirección de obra (una parte significativa pues supone, como en otras obras del autor, modificaciones permanentes y muy significativas con respecto a lo dibujado).
Inza publicó siempre el proyecto y la obra de Segovia con el nombre de los dos arquitectos a pesar de que los planos desde 1964 ya están únicamente firmados por él. Sí especifica en las publicaciones su autoría en la dirección de obra, de ahí la confusión de que a veces aparezcan dos nombres y a veces uno solo. Conociendo ahora la breve participación inicial de Dols, las posteriores versiones (todas clasificadas en el archivo) y las modificaciones de Inza se puede decir sin lugar a error que el autor real del proyecto es Curro Inza.

Los Postigo, tenían una fábrica familiar de productos cárnicos (los famosos embutidos de Cantimpalos) en el cercano pueblo del mismo nombre. La fábrica fue creciendo y necesitaba ser ampliada por lo que compraron un terreno de $52.000 \mathrm{~m}^{2}$ en la carretera de San Rafael, a la entrada de la ciudad de Segovia.

El encargo consistía en construir una primera fase (1963-66) de un complejo fabril de industria cárnica con una superficie de $16.000 \mathrm{~m}^{2}$. Antes de acometer este proyecto, Heliodoro Dols y Carlos Postigo llevaban un año reuniendo datos y habian viajado visitando fábricas de Inglaterra, Dinamarca, Alemania, Holanda, Francia y Estados Unidos, reuniendo una ingente cantidad de información actualizada sobre procesos fabriles. A estos viajes se sumó a partir de 1963 Curro Inza.

El cliente, Carlos Postigo, era, según Inza, un hombre de inteligencia natural y profundo conocimiento del negocio, un asunto que acabará por determinar algunos aspectos del proyecto como veremos más adelante.
Fábrica de Cantimpalos. Fuente: Archivo Inza

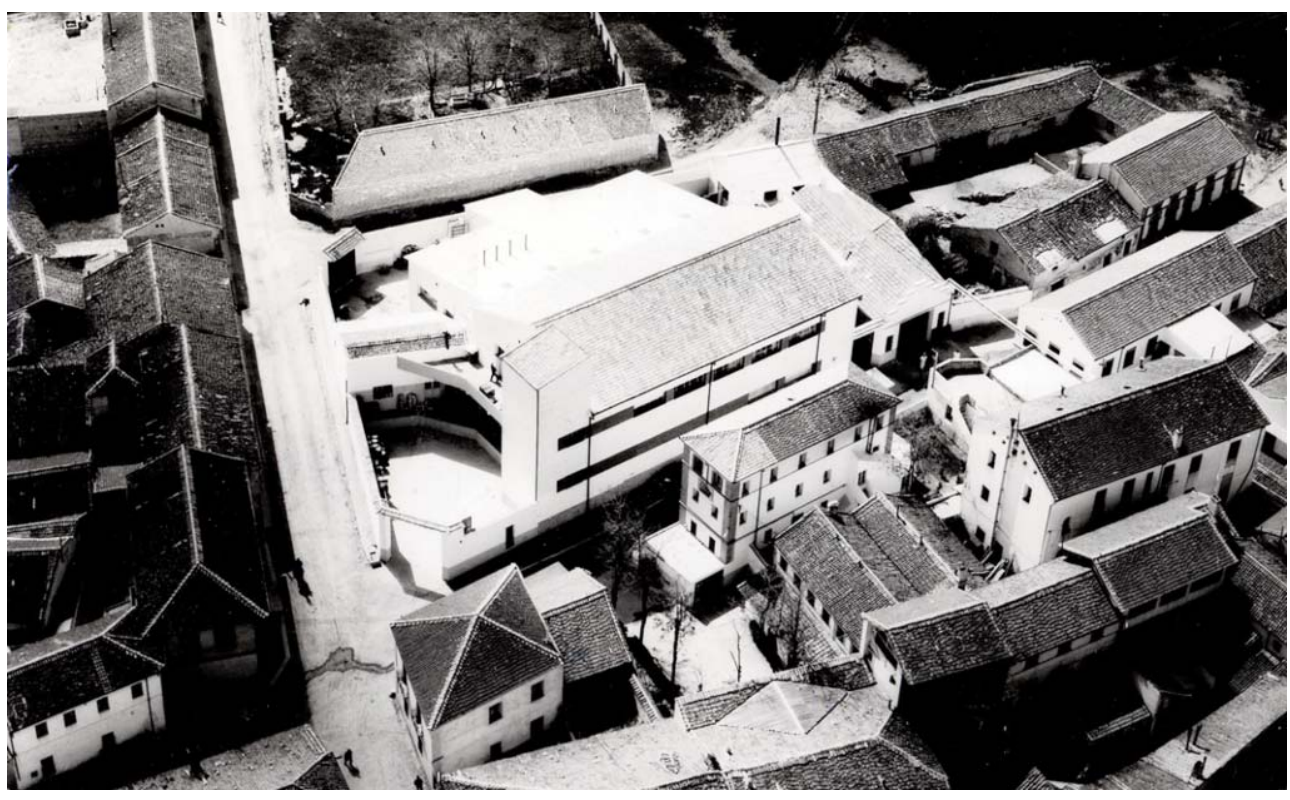




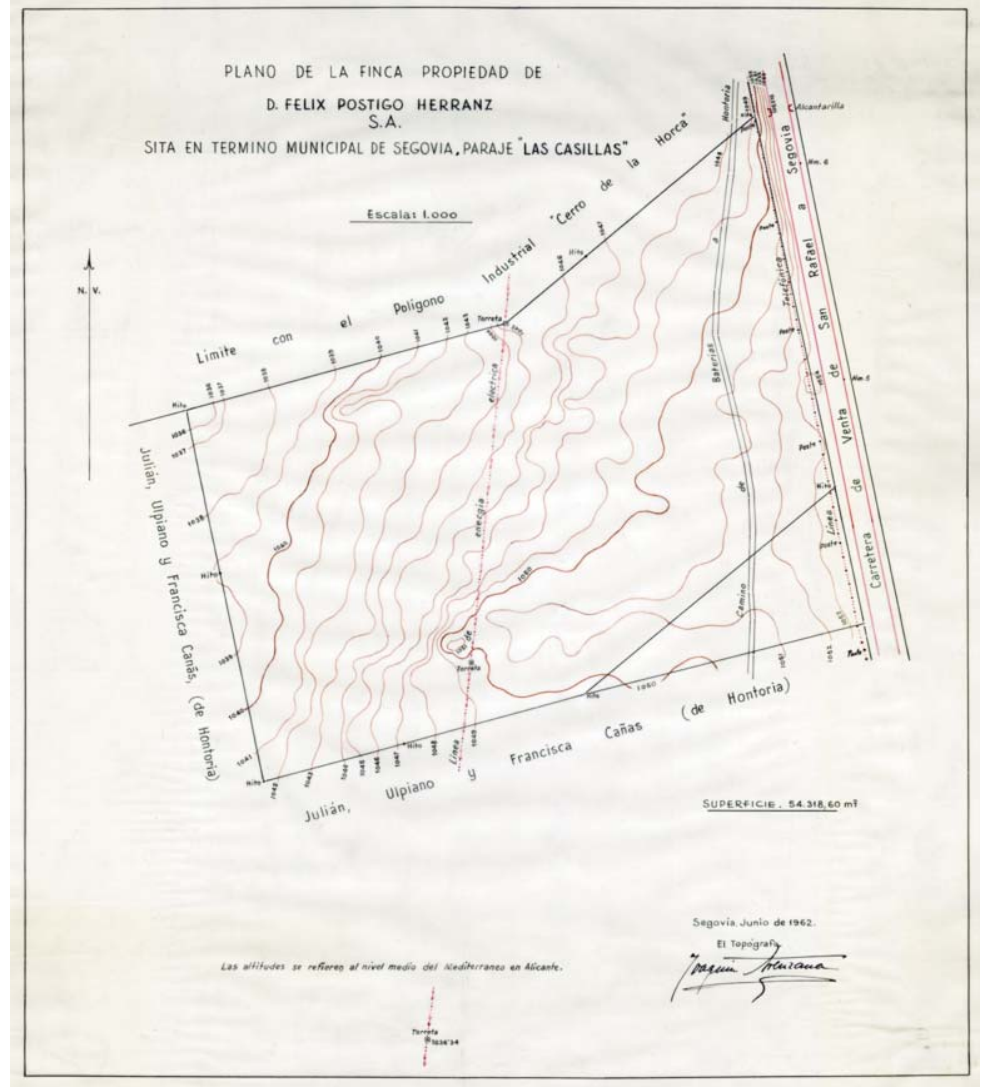

Solar de la fábrica de embutidos.1962. Fuente: Archivo Inza

\section{Las versiones del proyecto}

Centrándonos en la primera fase (19631966) es importante entender el proyecto como un proceso en permanente transformación y que duró varios años. La catalogación del archivo Inza nos permite, por vez primera, poder conocer y repasar las distintas versiones dibujadas así como los cambios que van ocurriendo en la dirección de obra

Muchas de estas versiones no son completas sino parciales y solo aparecen planos que modifican parcialmente el proyecto anterior. Las versiones dibujadas son:

- La primera versión: el Anteproyecto (febrero de 1963).

- La segunda versión: el Proyecto (mayo 1963).

- La tercera versión: modificaciones al proyecto durante 1964.

- La cuarta versión: modificaciones al proyecto durante 1965 .

\section{La primera versión: el anteproyecto}

Conseguir el encargo no fue fácil. Postigo puso a prueba a Inza y Dols. Entre los tres redactaron un anteproyecto y en paralelo la firma Postigo encargó a una empresa de especialistas suizos otro anteproyecto sobre el mismo tema con la idea de escoger entre ambos cuál se iba a realizar (Castro 1971). Desde el otoño de 1962 hasta el invierno de 1963, trabajaron unos seis meses en el anteproyecto. Inza recordará después "que los procesos de aprovechamiento del ganado porcino y del ganado vacuno eran muy complicados con lo que sólo para redactar el organigrama tardamos dos meses y esos datos terminaron ocupando varios DIN A1” (Inza 1966).

En esta primera versión vemos que efectivamente el organigrama es tan importante que no se presenta aparte en las memorias sino que constituye los primeros planos del proyecto dibujado. En un proyecto que tiene quince planos de arquitectura, los organigramas ocupan los seis primeros A1. (Inmediatamente después se presenta la planta general en el plano $\mathrm{n}^{\circ} 7$ ).

Por tanto la primera pista para entender el proyecto es que la planta de la fábrica, tan orgánica a primera vista, es el resultado casi literal de dibujar y grafiar un proceso de fabricación. (El interés de Inza por el organigrama como herramienta influirá en su labor en la revista donde empieza a publicar muchos de ellos a partir de esa fecha). ${ }^{14}$

Esta primera versión del proyecto es la única que incluye todo el proceso de fabricación. De hecho el primer punto del organigrama son los establos de espera y los mataderos para el ganado, hasta terminar en las áreas de empaquetado, conservación y expedición, y existe un camino perimetral de carga y descarga que rodea toda la fábrica. A su vez las secciones describen un edificio de una planta, donde la mitad de su superficie tiene un sótano y un edificio de oficinas de tres alturas sobresale sobre el conjunto.

La disposición de los volúmenes en el terreno "ha venido determinada, en primer lugar por los organigramas de producción y también adaptada en lo posible -sobre todo para la disposición de sótanos y almacenes- a la topografia. El terreno es totalmente granítico, y los movimientos de tierra por tanto costosos y la cimentación muy sencilla”. ${ }^{15}$

Una condición que a la postre fue determinante para entender la estructura elegida y el planteamiento general del edificio fue el aspecto higiénico de los pavimentos, paramentos y techos del edificio. Por una cuestión higiénica dentro del proceso de fabricación y manipulación de los alimentos, se le exigió a Inza que los techos fuesen absolutamente planos al interior, lisos, sin rincones y fáciles de limpiar. Por tanto no podrian plantearse soluciones 

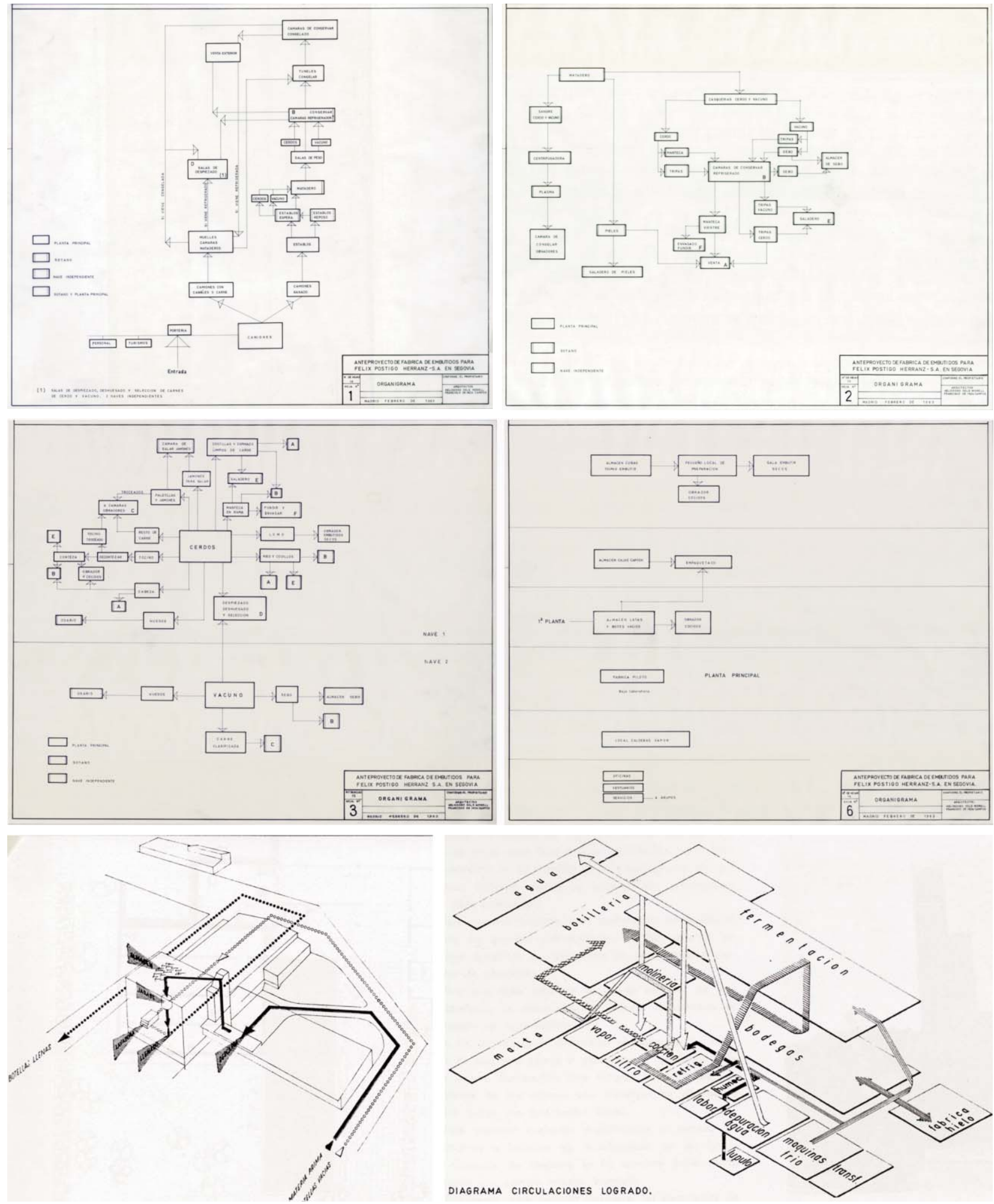

Arriba y medio. Anteproyecto Diagramas. Fuente: Archivo Inza

Abajo. Edificio para embotelladora. La Coruña.1963.

Fernández Arbalat y Tenreiro. Fábrica de cervezas El Águila. Córdoba.1962. R. De la $\mathrm{Hoz}$ estructurales donde existiesen cerchas ni tirantes. En esta primera versión ya se dibujan unos forjados planos aunque aún no se especifica la estructura que garantizara ese condicionante.

Encima de los forjados planos existen unas cubiertas longitudinales a dos aguas con algunas áreas en diente de sierra, lo que produce un cierto movimiento en los alzados. Las fachadas aún muy indefinidas (según la memoria serán muros de carga de un pie y de ladrillo visto), y tienen los mismos huecos en las naves que en el edificio de oficinas.

En las plantas de este anteproyecto apenas se refleja la estructura mientras en la memoria se avanza un sistema estructural aún muy genérico así como los materiales 
Anteproyecto planta general. Fuente:

Archivo Inza

Anteproyecto. Alzados

y secciones. Fuente:

Archivo Inza
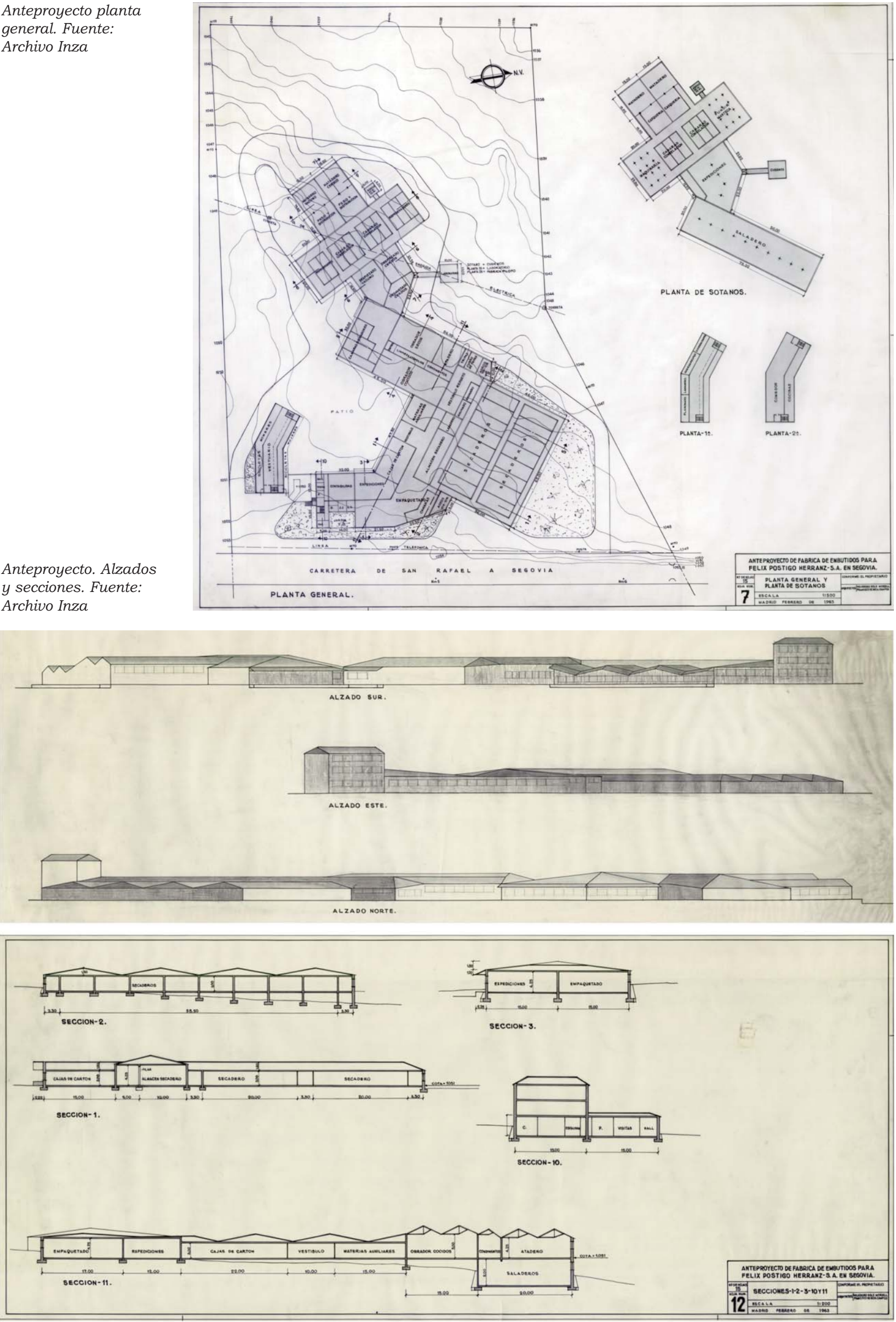
Segunda versión Planta general.1963 Fuente: Archivo Inza

Segunda Versión. Plantas cimentación y baja.1963. Fuente: Archivo Inza

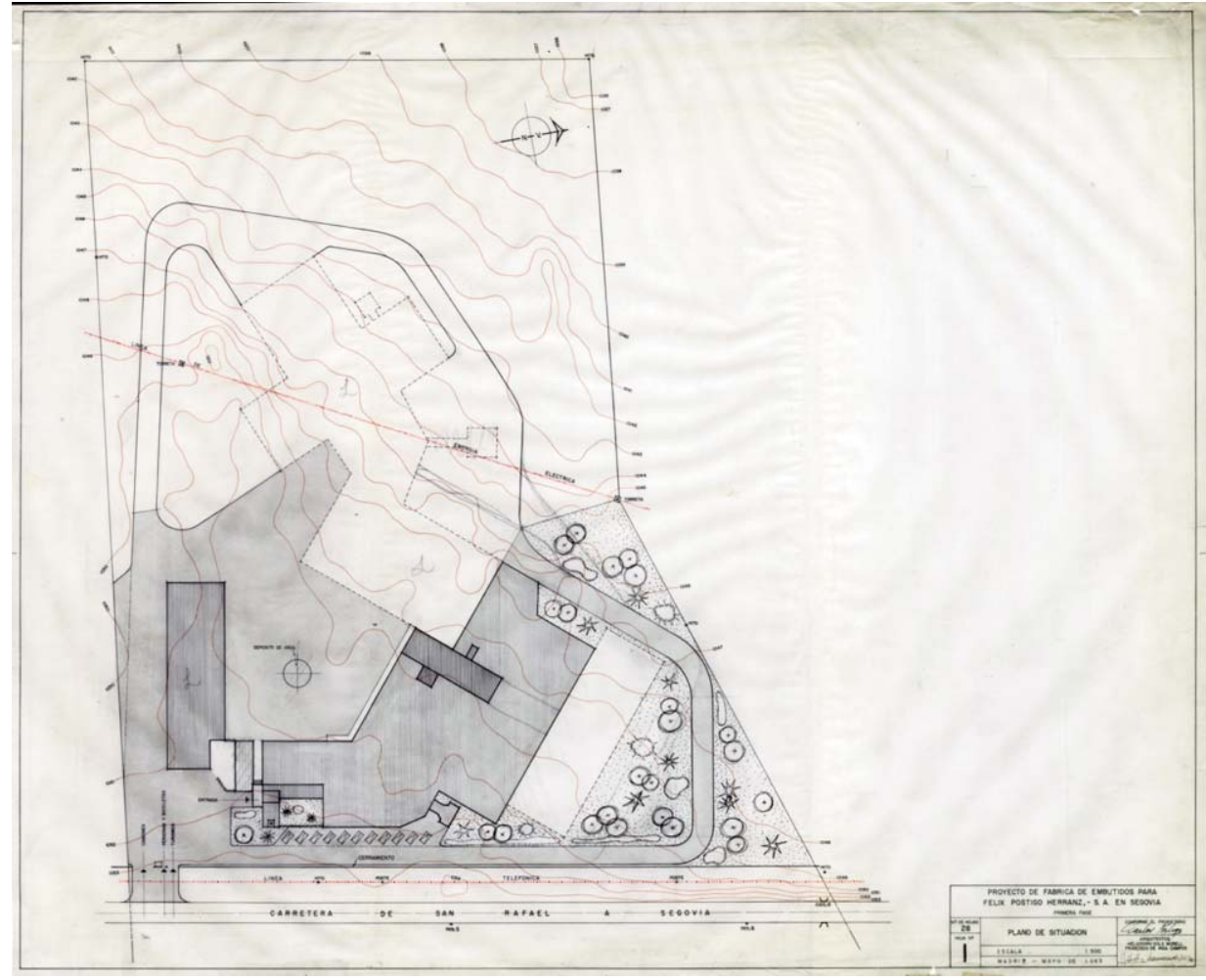

de cubierta a utilizar. Se dice que en las zonas fundamentales de la fábrica se emplearán módulos de 15 metros de luz pero se prevé el empleo de soportes en aquellas zonas en las que la distribución interior lo permita. Sin embargo en la zona de mataderos y distribución que exigen luces minimas de 15 metros y gran iluminación, se emplearán cubiertas de estructura metálica tipo Rouz Fiéres*, que presenta por el interior un cielo-raso continuo que facilita la limpieza. Los faldones con elementos transparentes se orientarán a norte. Y exactamente el mismo sistema de cubierta se empleará, con orientación semejante, en las zonas de obradores. Además el elemento de cubrición que se prevé para toda la fábrica es la teja árabe. En las distintas zonas, se organizarán cubiertas por forjado cerámico plano con tabiquillos para lograr la pendiente necesaria. Y en aquellas zonas que requieran iluminación cenital, se instalarán lucernarios esféricos de material plástico. ${ }^{16}$

El anteproyecto de Inza-Dols se comparó con el de los suizos y finalmente recibieron el encargo de redactar el proyecto, pero a lo largo del invierno de este año los Postigo deciden que la nueva fábrica de Segovia no debe cubrir el proceso industrial completo y que hay que separar el proceso

*Probablemente se refiere al sistema belga de cerchas metálicas para naves, Roux Frêres, introducido en España por esos años. N. del ed. 

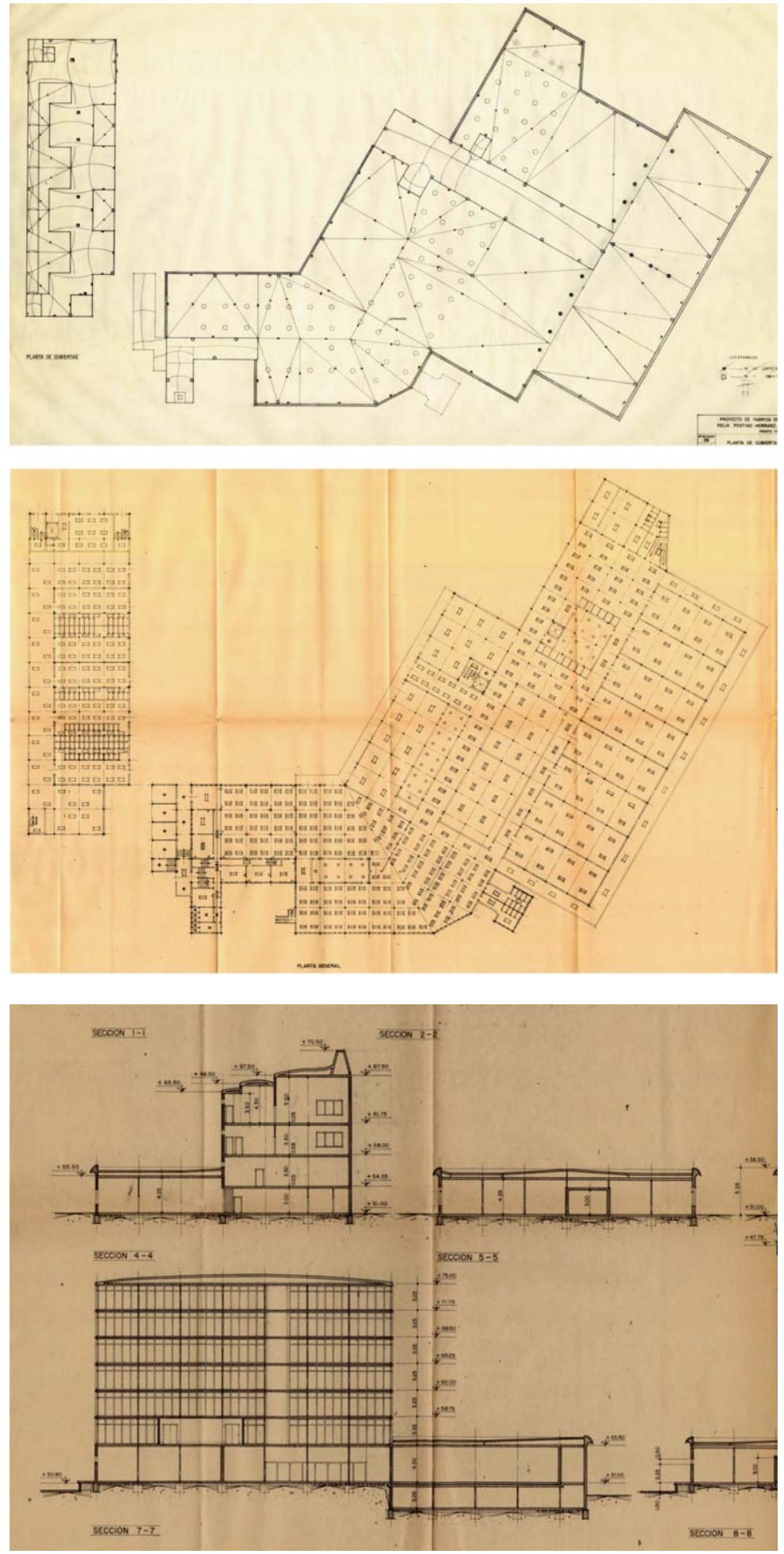

Segunda Versión. Plantas cubiertas e instalaciones.

Secciones. 1963.

Fuente: Archivo Inza industrial en dos partes: por un lado la fabricación y por otro, la manufactura.

La decisión fue que en Cantimpalos se fabricarian los embutidos y se mantendrían los establos y los mataderos de carne de vacuno y de cerda, mientras que la nueva fábrica de Segovia se elaborarian las últimas fases del proceso de manufactura de los productos cárnicos, es decir, almace- namiento, expediciones, cámaras frigorificas y secaderos. Así la fábrica debe entenderse como una ampliación de Cantimpalos por donde, en ese momento, era más necesario: por los procesos últimos de fabricación. Quizás posteriormente pudiese albergar la parte de fabricación pero a partir de mayo de 1963 la fábrica como decía Inza "se había empezado por la cola".

\section{La segunda versión}

Se redacta la segunda versión (mayo 1963) que es la que se visó en el Colegio de Arquitectos de Segovia (y de la que aún hay una copia en el Archivo Provincial de Segovia pero no en el Colegio) y por tanto contiene los dibujos que hasta ahora se han divulgado del edificio. En esta versión el proyecto alcanza los dieciséis mil metros cuadrados y corresponde a la parte final del proceso productivo, consta de: bloque de oficinas (administración, contabilidad, despachos), almacenes (en sótano), salas de empaquetado, expediciones, cámaras frigoríficas, secaderos artificiales de embutido y secaderos naturales (en una torre de seis plantas). Para Inza esta versión (que es la que se termina construyendo) "consta precisamente de aquellos elementos que no son propiamente fabriles" (Inza 1966).

Al limitarse esta segunda versión a la parte dedicada a elaboración, se reduce drásticamente la superficie en planta baja y en sótano. Se distinguen en el conjunto dos edificios: uno pequeño rectangular al sur y otro grande de perímetro irregular al norte. El primero tiene dos alturas (aseos y vestuarios en planta baja y viviendas en planta primera), mientras que el edificio de perimetro irregular tiene una altura (almacenamiento, expediciones, empaquetado y cámaras frigorificas) y dos elementos verticales: un edificio de oficinas de cuatro plantas y un edificio de secaderos naturales de siete plantas.

Inza entendió que se exigía y que había que buscar un sistema estructural que permitiera un techo absolutamente plano, sin cerchas, ni tirantes y a esta condición vinculará el sistema estructural elegido y por tanto quedó descartado cuanto no fuera lisura. En consecuencia, matiza la estructura de la primera versión y plantea una modulación de $5 \times 5$ y $5 \times 8$, conveniente para hacer frente a las dimensiones de los obradores de fabricación y de los secaderos artificiales (Castro 1971). Además el programa (al haber eliminado las partes de mataderos, animales y fabricación), no exigía grandes luces. Por tanto se entiende que Inza proponga un sistema estructural de un módulo repetido para todo el edificio 

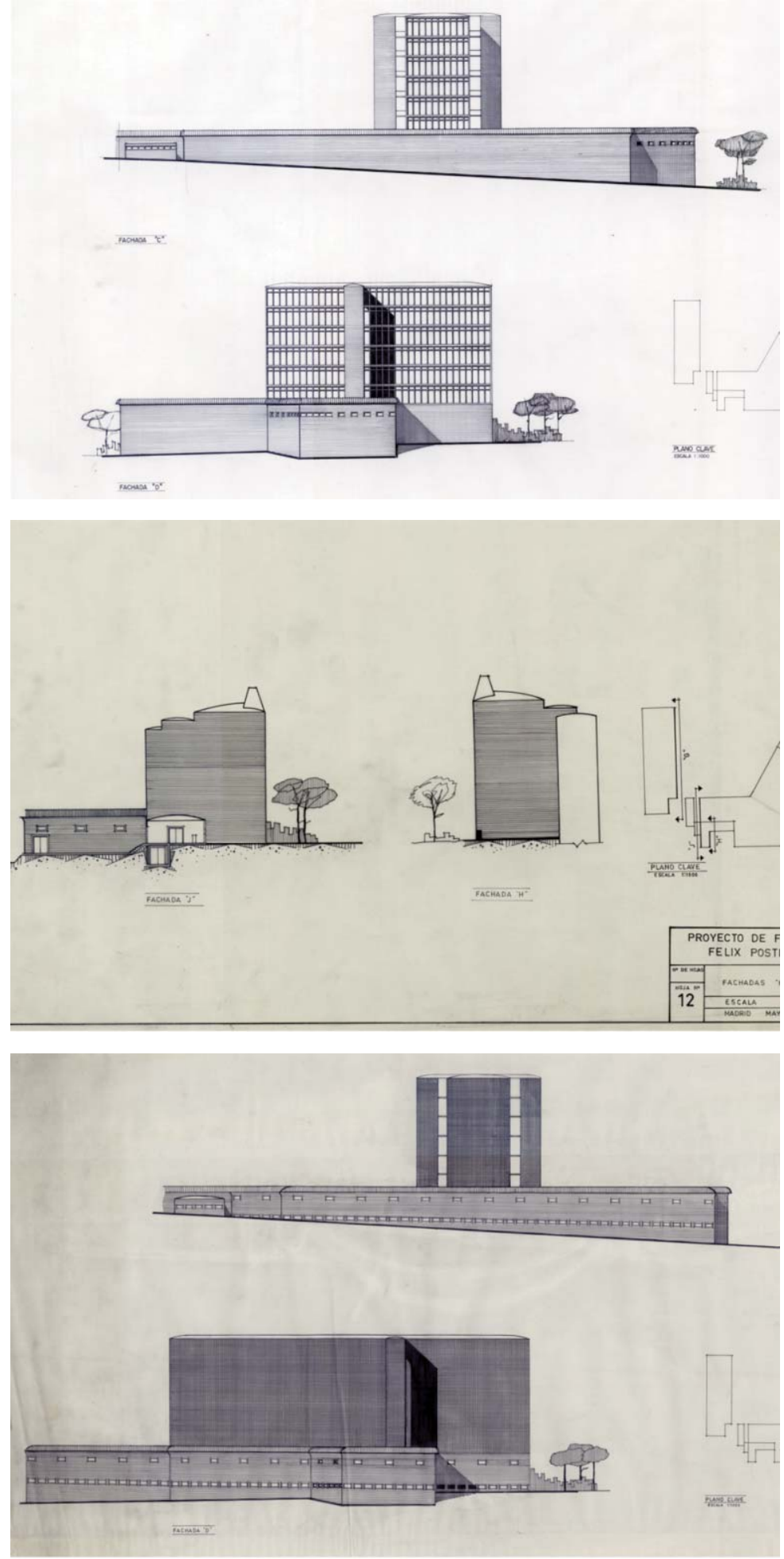

Arriba. Segunda Versión.

Alzados. 1963. Fuente: Archivo Inza

Centro y abajo.

Tercera versión.

Alzados. 1964. Fuente: Archivo Inza metálica, con pilares metálicos vistos y con una dimensión modular que considera no perjudicial para el funcionamiento del trasporte interior que en las fábricas de se quizás preparado para acometer una gran estructura (ya había mirado a Candela, Sota, etc) finalmente no será necesario pues entiende que los requerimientos de Postigo se pueden hacer con una estructura pequeña, casi doméstica.

En las plantas ya se reflejan perfectamente las decisiones estructurales tomadas. Se aprecia una cimentación, que en este terreno granítico se propone de baja profundidad, con un pozo por cada zapata y una zanja de atado de los cimientos de los muros de carga:

"Se proyecta una estructura de hierro con pilares de tubo y placa armada en dos direcciones, sin vigas. Esta solución está prevista para toda la fábrica, excepto en la torre de secaderos naturales, en las que está previsto un forjado del mismo tipo y pilares de perfiles en U. Este tipo de forjado -placa armada en dos direcciones-, se considera muy adecuado para el tipo de distribución de pilares. Es decir para elementos simétricos de 5 x $5 \mathrm{~m}$. (..) Sin embargo en la zona de secaderos artificiales, modulada por causa de necesidades de funcionamiento en elementos de $5 \times 8$ $\mathrm{m}$, se prevé un forjado curvado apoyado sobre perfiles laminados formando pórtico con soportes de tubo. La luz de forjado es de $5 \mathrm{~m}$ ". ${ }^{17}$

Los forjados, apoyados en las alas y cordones inferiores, permiten un techo absolutamente plano y en el interior, quedan las vigas ocultas en el vacío de la cubierta. Los muros de cerramiento de la fábrica y los alzados de esta versión ya reflejan que se trata de un edificio de ladrillo (de un pie de ladrillo macizo a cara vista según la memoria).

Inza mimetiza los edificios que tienen una condición más domestica (el de vestuariosviviendas y el de oficinas) y utiliza en ambos los mismos huecos, las mismas chimeneas, etc.

En las naves se eliminan las cubiertas inclinadas de la primera versión y se proyectan forjados planos con cubierta vegetal. Los edificios en altura (vestuarios, oficinas y secaderos naturales) como puede apreciarse en las secciones y alzados, se distinguen de la naves al montarse sobre el forjado plano una bóveda tabicada de rasilla con doble tablero.

\section{La tercera y cuarta versión} embutidos suele ser por cadenas transportadoras y carretillas. Aunque Inza estuvie-
La tercera versión son las modificaciones que se le realizan al proyecto durante el año 1964 una vez comenzada ya la obra. 


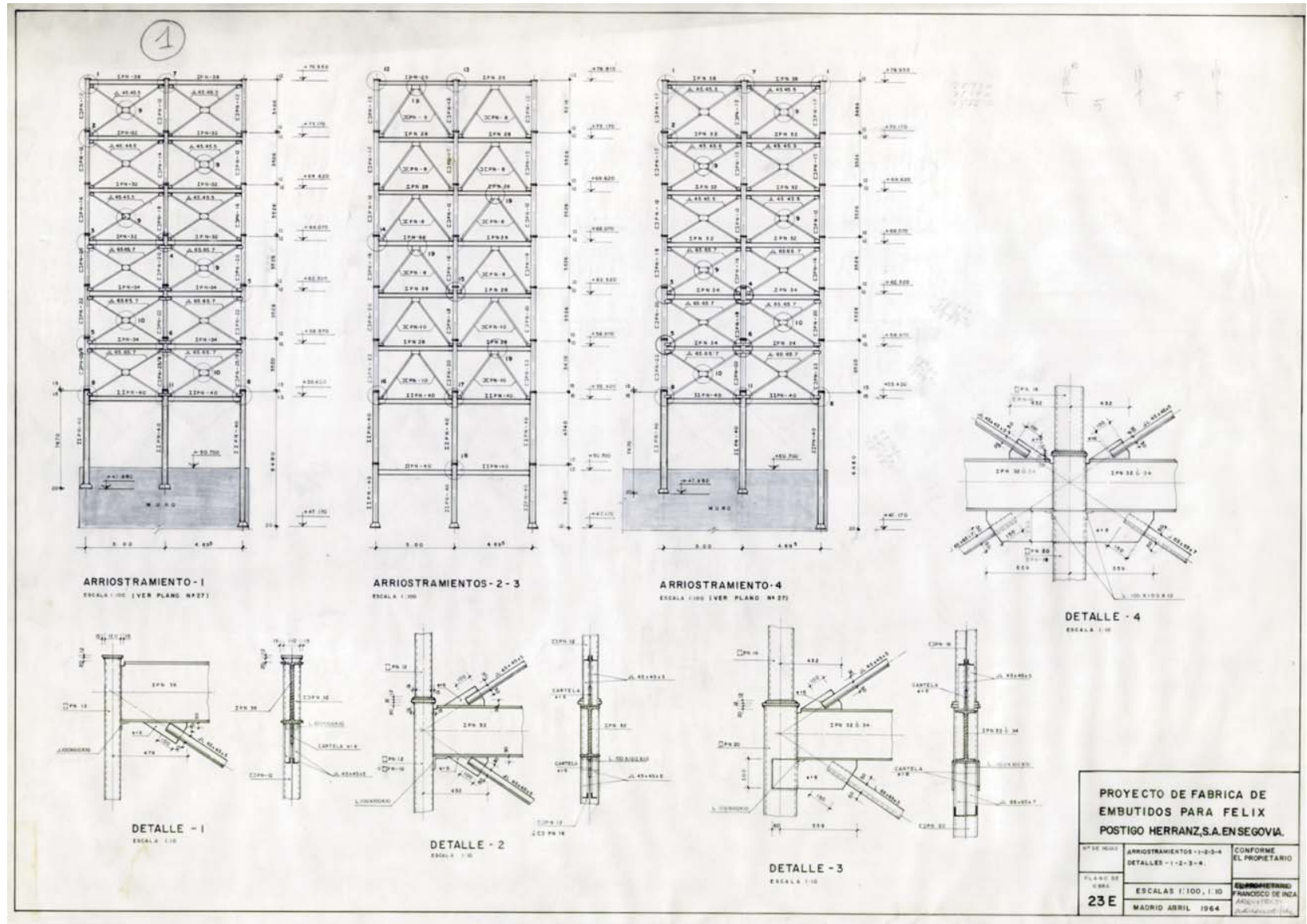

Tercera versión. Detalles. 1964. Fuente: Archivo Inza

\section{Cuarta Versión} Alzado y sección.1965. Fuente: Archivo Inza
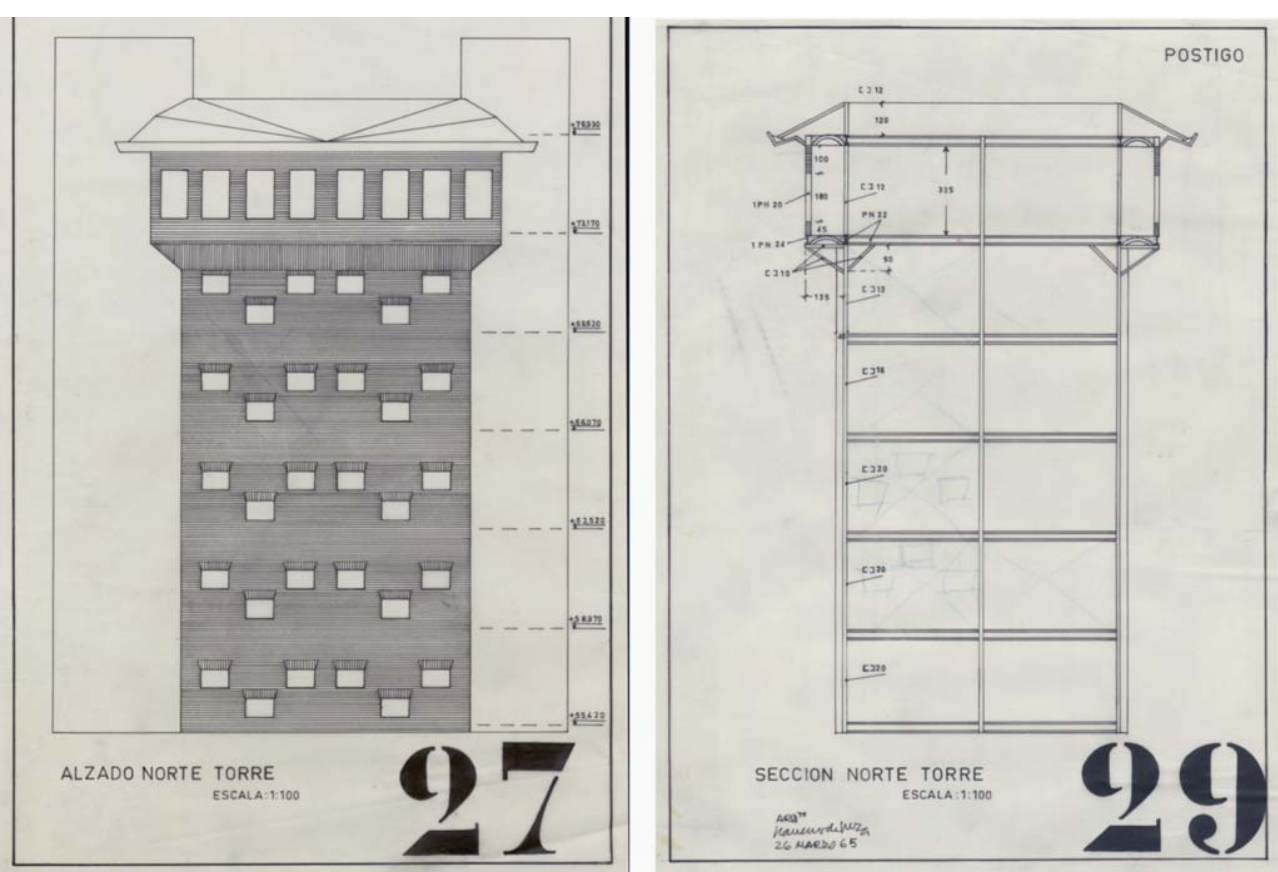

Se redibuja el saneamiento y los accesos (marzo 1964), la estructura (abril 1964), la cubierta y los alzados (mayo 1964) y la tabiquería de las oficinas (diciembre 1964). De esta documentación lo más destacable es, por una parte, la definición completa de la estructura hasta sus detalles de ejecuto que no estaba definida en el proyecto anterior. Y por otra parte las fachadas prácticamente opacas que momentáneamente plantea Inza y que serán desechadas en obra. ción (voladizos, atirantamientos, etc) pues- 

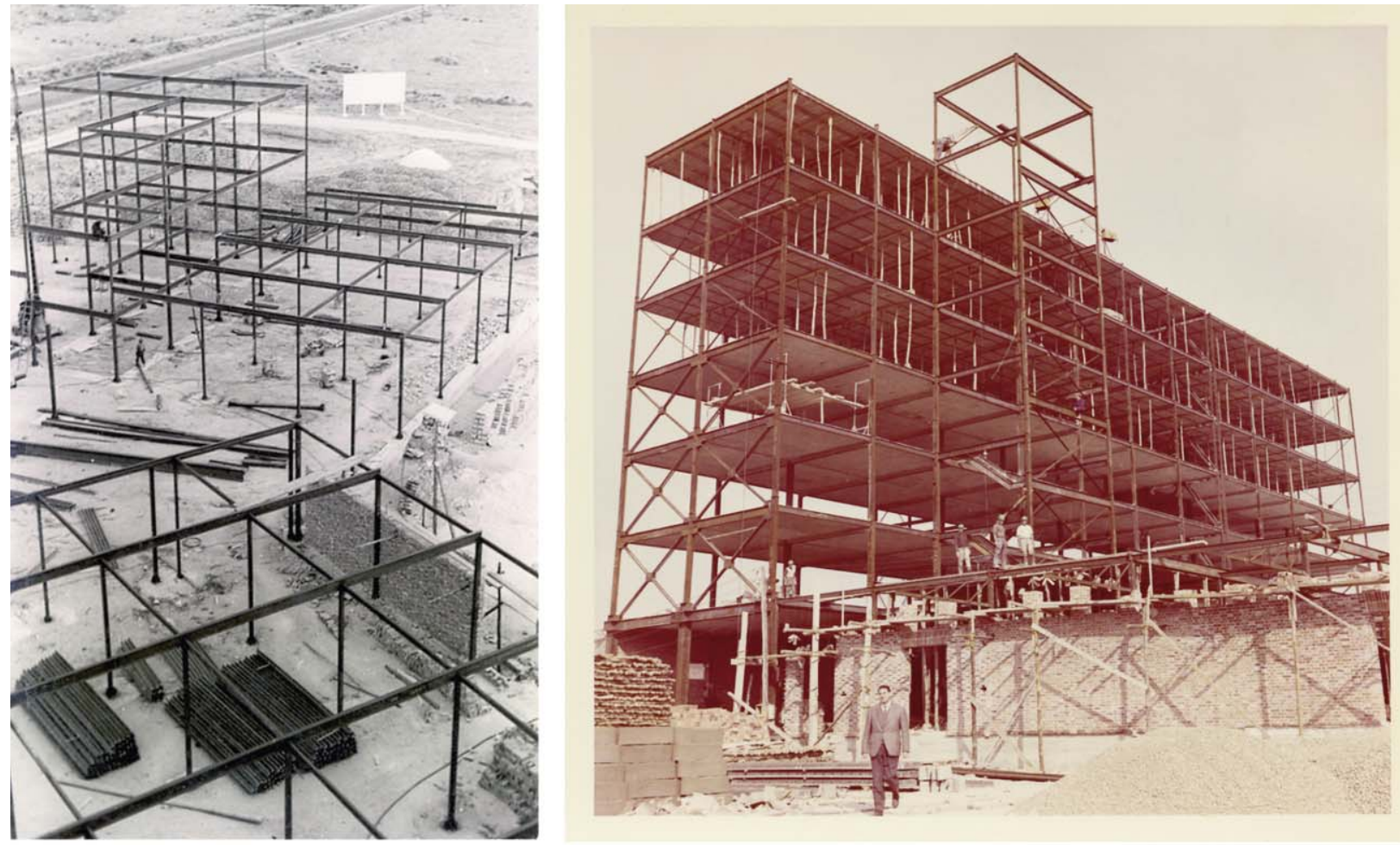

Estructura. Fuente: Archivo Inza

Construcción.

Fuente: Archivo Inza
La cuarta versión son los dibujos correspondientes al año 1965 que incluyen algunas modificaciones como la puerta exterior de oficinas (julio 1965) y la urbanización del acceso o dibujos que añaden información como partes de la estructura que estaban por hacer.

Pero lo más importante son los dibujos correspondientes a las ventanas de la torre de secaderos (octubre 1965). En el archivo del arquitecto sólo han aparecido documentos de las fachadas cortas. En ellos se ven las nuevas decisiones tomadas como son el ensanchamiento de la torre y sobre todo la elección de un un acabado definitivo.

Tras pasar por distintas versiones (fachadas con muro cortina, fachadas opacas, etc.) la torre de secaderos se construirá maciza y con huecos aleatorios en sus alzados cortos.

Si bien no ha aparecido el plano de los alzados largos, estos se construyen igual pero con huecos seriados y limitados por la estructura metálica. Estos alzados son más permeables pues la torre está orientada para que los vientos dominantes traspasen los alzados longitudinales y curen los embutidos.

(A pesar de que la obra terminó en 1966, no se han encontrado ningún documento gráfico fechado en ese año).

\section{La construcción de la fábrica}

Finalmente el proyecto de 1963 es el que se construyó. La obra duro desde finales
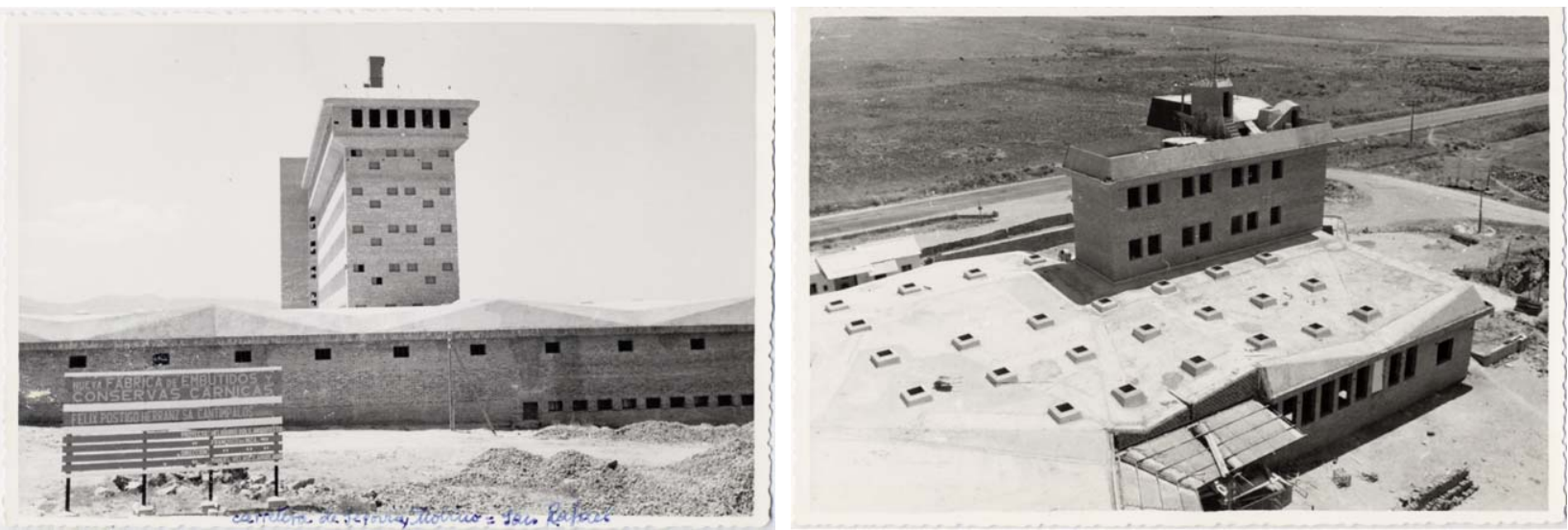
del verano de ese año prolongándose durante tres años y, como es habitual en el autor, lo dibujado y lo visado no coincide en muchos aspectos con lo construido. Algunas de estas modificaciones se realizaron en obra y no queda registro gráfico en el archivo. (Estas modificaciones son lo que he denominado como "tercera y cuarta versión del proyecto", es decir los planos dibujados en paralelo a la obra en 1964 y 1965. Ninguna de estas modificaciones fue visada, ni existe copia fuera del archivo personal, por lo que eran desconocidas hasta hoy).

Observando las fotografias del edificio en construcción vemos que no existen modificaciones en la planta y que efectivamente se construye con una estructura metálica y cerramientos de ladrillo. Sin embargo las cubiertas, los alzados y otros aspectos poco tienen que ver con el proyecto visado y parcialmente publicado a día de hoy.

Teniendo como referencia local e internacional, la fábrica de Cantimpalos y las instalaciones que habia visitado en el extranjero, Inza había observado que las fábricas estaban en constante crecimiento. La mejor de ellas estaba en un pueblo cercano a Bristol y desde sus orígenes en el siglo XVII habia seguido creciendo:

Orfanato de Van Eyck y Baños de Trenton de Kahn

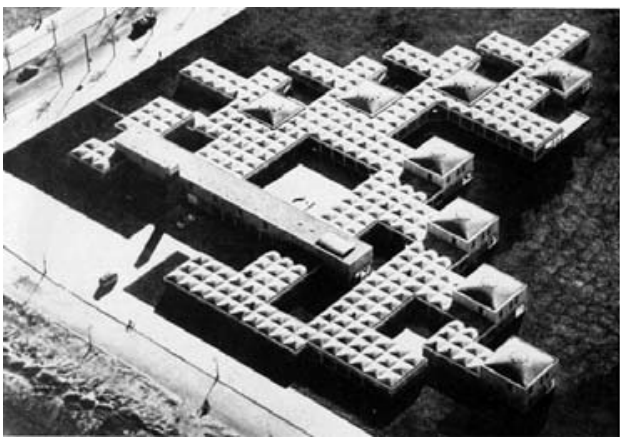

"Lanza puentes por encima de las calles, para unir entre sí nuevas y viejas dependencias, va ocupando casas... Es decir, la fábrica va ocupando el pueblo, como lo puede copar un ejército de ocupación. El pueblo es la pura fábrica. Y en España, Cantimpalos es un ejemplo interesantísimo. Cantimpalos pueblo está ocupado por la fábricas de embutidos. Se saltan con puentes y pasadizos las calles, cuando hace falta y las fábricas siguen creciendo y están vivas desde hace doscientos años casi.

Si esto ocurre en Cantimpalos o Bristol, y en Dinamarca pasa otro tanto, ello significa que las fábricas nunca se quedan estáticamente terminadas, como tampoco las ciudades. Madrid no está terminado... $\mathrm{Y}$ con las fábricas pasa lo mismo que con las ciudades. Cosa muy importante para diferenciar lo que es la Arquitectura de viviendas, por ejemplo, de los que es la Arquitectura Industrial. La Arquitectura industrial es algo que nunca se termina, que nunca está acabada. Y creo que el secreto de este tipo de arquitectura es dotarla de una capacidad de crecimiento, confiriéndole una autentica elasticidad". (Castro 1971)

Parece claro que al iniciarse la obra la idea de lo "no terminado", de la elasticidad y del crecimiento se convierte para el arquitecto en un valor a explotar. Desconfia de las grandes luces en las fábricas que ha visto: “(...) Debo decir también que he visto las mejores fábricas de Europa y no tienen nada especial en cuanto a grandes luces de 150, 100, o de 80 metros de luz libre, que encarece mucho la obra y crea unos serios problemas de iluminación”. Explica que para él la elasticidad era haber escogido una modulación sencilla ( $5 \times 5$ y $5 \times 8 \mathrm{~m})$ que fue elegida por la premisa de garantizar la limpieza de los techos, lo cual se

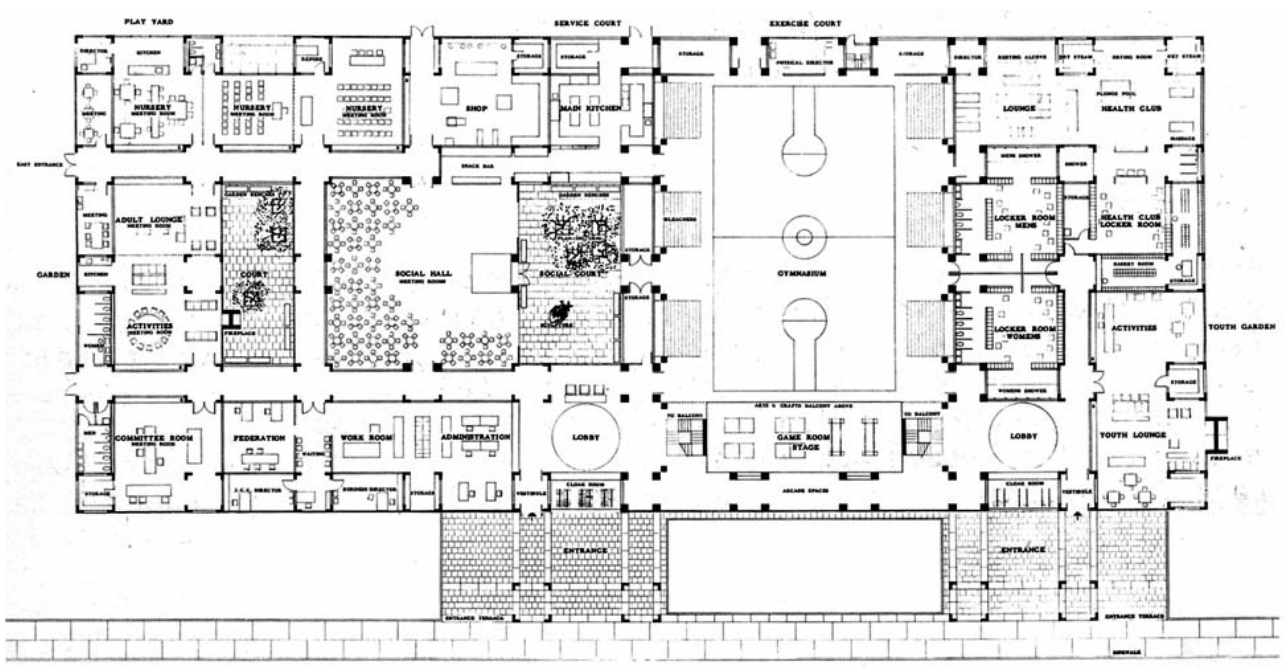



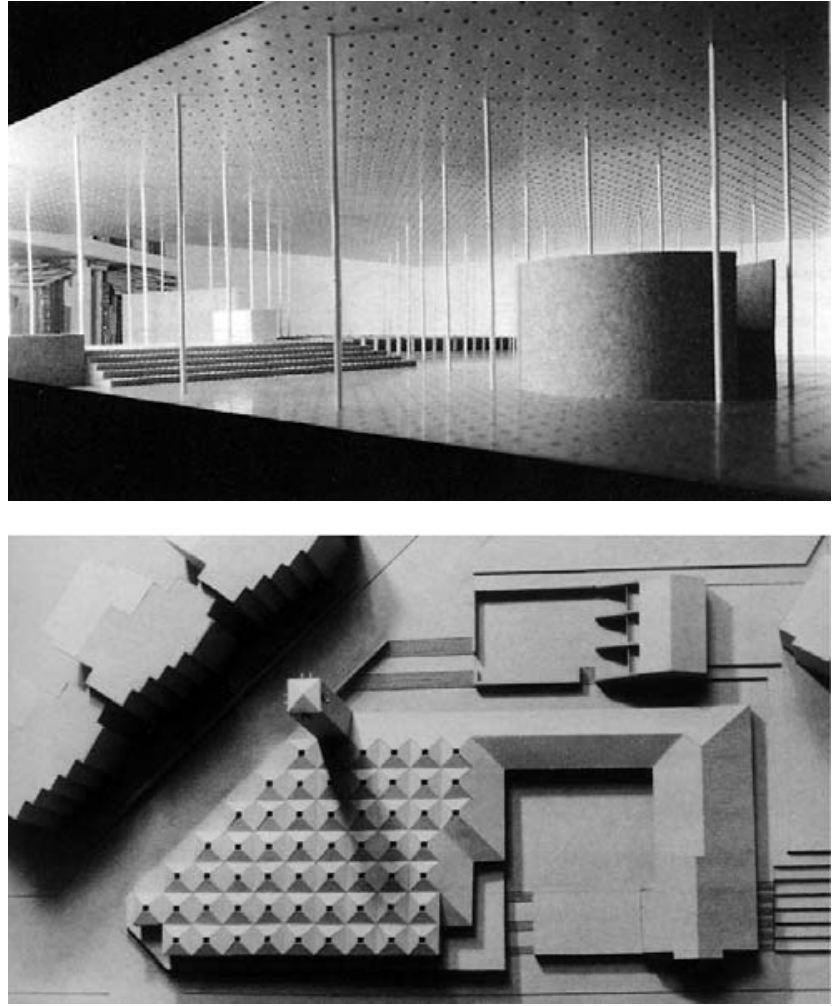

Concurso Cuenca e Iglesia de Almendrales. García de Paredes

La fábrica recién finalizada. Octubre 1967. Fuente: Archivo Inza quedan emplazados a bastante altura sobre los forjados" (Castro 1971).
Lo que aquí interesa desde un punto de vista compositivo es que establece una vinculación entre módulo estructural y la iluminación cenital que permiten un crecimiento libre. Se puede decir que en Segovia repite los módulos en cubierta mientras varía el proyecto en la distribución interior y en ese sentido su referencia sería el Orfanato de Van Eyck. También es más Van Eyck (y más Bruselas) al optar por un sistema que le permite un perímetro libre. $\mathrm{El}$ perimetro y la forma final del edificio, en ese sentido, son irrelevantes. Dependen de una ley de crecimiento y no de una decisión a priori (una pauta característica de Inza en cualquier caso).

Es interesante reparar por un momento en cómo Colin Rowe (1978: 144) establece una discusión y distinción espacial de Kahn versus Mies, que puede explicar a Inza: Inza se parece a Mies cuando establece un techo plano continuo y un espacio pautado por pequeños pilares, sin embargo se trata de un techo liso no portante (un falso techo), una operación cosmética para mejorar la higiene. Por otra parte no ahueca la estructura como hace Kahn, y no asocia elementos como la recogida de agua y la estructura, como ocurría en los Baños de Trenton (y a su vez en Bruselas y Almendrales). Aun así, la fábrica le debe más a este autor pues finalmente el grueso del material se lo lleva el perfil montañoso de la cubierta.

Terminará pareciendo una gran estructura cuando en realidad tiene una estructura pequeña. La reducción del programa de la

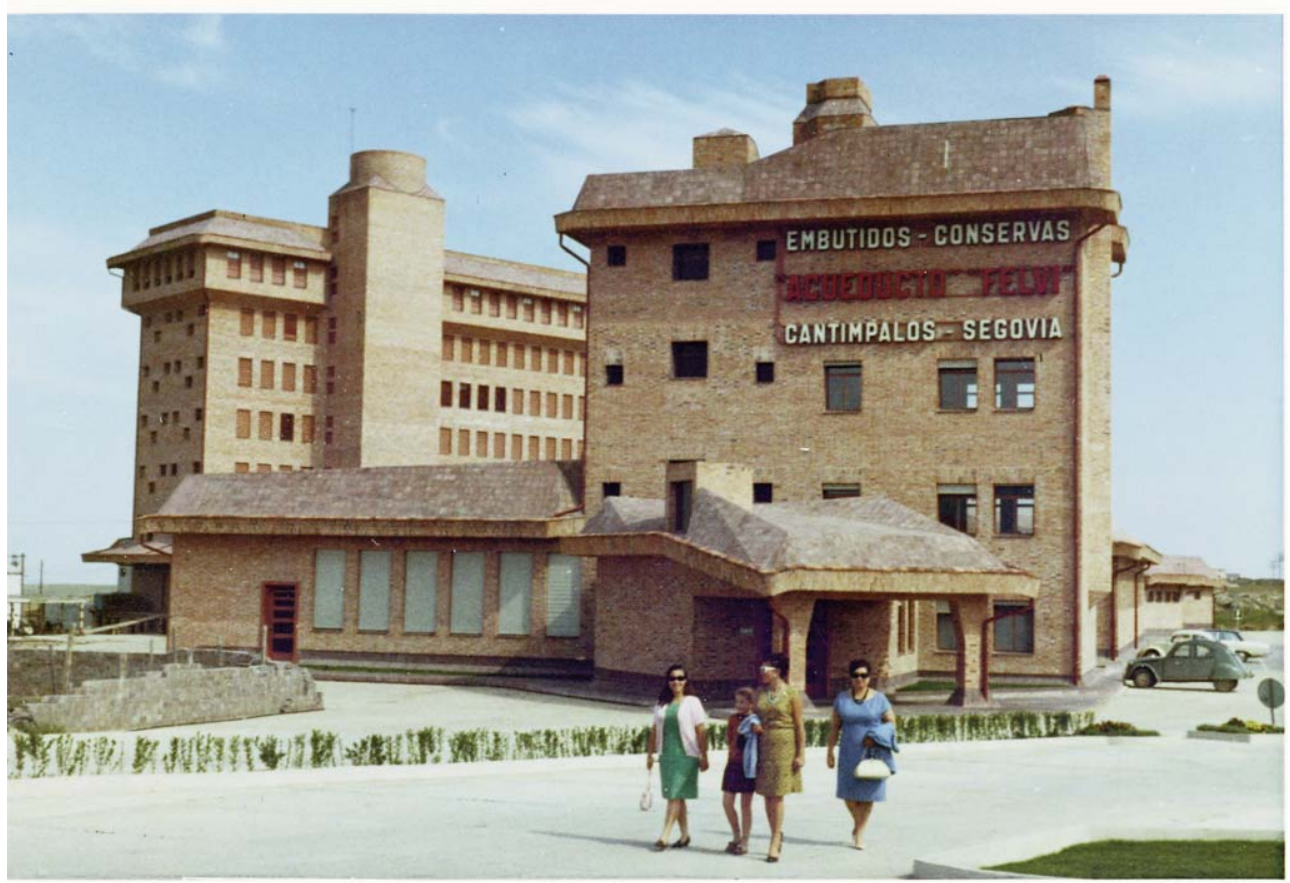


segunda versión le permite concentrarse en un módulo. Desaparece la estructura grande y aparece el matbuilding: junta, superpone y adhiere células repetidas que le permitan crecer espacialmente de forma operativa y económica desde un punto de vista instrumental. Inza trabaja en la fábrica con la adición asociada a lo estructural y a unos módulos ya definidos en la segunda versión, dónde ya se intuía el "edificio estera" (trama de $5 \times 5$ y $5 \times 8$ como caso especial).

Entre las influencias internacionales de fábrica de Inza estarian Kahn, el Team X y Van Eyck. (En años posteriores irán apareciendo en Europa proyectos que completarán la familia de edificios de crecimiento celular como el Hospital de Venecia (196466) de Le Corbusier, el Centraal Beheer de Apeldoorn (1968-72) de Herman Hertzberger o la Universidad Libre de Berlin (19641973) de Candilis, Josic y Woods). ${ }^{18}$

Entre las influencias nacionales (además de Bruselas) es imprescindible decir que se intuye la influencia decisiva del camino paralelo que, sobre el tema de la adición, recorre José María García de Paredes.

En 1960, en el Concurso de la Iglesia de San Esteban Protomártir de Cuenca, mientras Inza hace un ejercicio aaltiano con Fernández Alba, García de Paredes depurará su modelo de adición celular planteado en su Pabellón de España de la Bienal de Venecia (1955). En Cuenca logra unas fotos de los interiores de la maqueta que han quedado en el imaginario de la arquitectura española de la segunda mitad del s. XX. Un espacio construido mediante la repetición de un módulo de planta cuadrada apoyado en cuatro pilares y que logra un espacio isotrópico derivado de la mezquita de Córdoba, donde sólo dos pequeños elementos como el baptisterio y el presbiterio rompen la a-direccionalidad del espacio.

El de Cuenca es el anticipo de la brillante Iglesia de Almendrales (1961-64), 19 proyecto final de una serie (como en el caso de Inza) y el único que García de Paredes llegará a construir de toda su investigación sobre la adición como mecanismo proyectual.

Almendrales influirá decisivamente sobre la fábrica de embutidos, también único edificio construido por Inza dentro del tema de la arquitectura y el crecimiento. El hecho de que se hagan prácticamente en paralelo hace pensar que la influencia de la obra Almendrales sobre Segovia habria que buscarla en los conocimientos que Inza pudo tener del proyecto dibujado.

\section{Conclusiones}

Cuando Inza recibe el encargo de la fábrica ya había demostrado, en encargos previos, estar interesado en el uso de "métodos aditivos" para producir sus proyectos. $\mathrm{Y}$ en los años que fue redactor jefe de la revista Arquitectura, hay constancia de que conoce y publica ejemplos de edificios modulares nacionales e internacionales.

El hecho de que Inza estuviera atento a estos asuntos compositivos vincula su obra con los intereses de sus coetáneos.

Sobre la fábrica se puede hacer una primera lectura cómo ejemplo de matbuilding donde el crecimiento modular es la herramienta predominante.

Desde el punto de vista de las plantas del proyecto, la fábrica es desde el principio la trasposición de un diagrama, a pesar de que ciertas formas externas nos puedan confundir. Sobre ellas se implanta un sistema claro, modular y eficaz sin pretensión estilística.

Las plantas evolucionan poco en las distintas versiones, sin embargo los requerimientos funcionales (de oficinas y secaderos) así como la incertidumbre sobre la fachada más adecuada, hace que los alzados y secciones varien en el tiempo. Es ahí (y no en el plano horizontal) donde el proyecto sufre fuertes variaciones.

Es habitual en la obra de Inza que las influencias externas sobre sus obras no se deban a aspectos tipológicos o del mismo uso. Esto hace entender como natural la influencia que sobre la fábrica de Segovia tiene la iglesia de Almendrales en aspectos como la estructura, la planta (tiene un módulo similar de $4.2 \times 4.2 \mathrm{~m}$ ), y la iluminación, aunque sus recursos sean más ortodoxos y menos ambiguos. (De hecho en Almendrales la estructura, la recogida de agua, la construcción y el perfil del lucernario coinciden y se corresponden, cosa que no ocurrirá en la fábrica castellana dónde estos elementos se disocian y el arquitecto mantiene una actitud más heterodoxa).

En cualquier caso hay algo de especular en ambas series y en dos arquitectos que, en este punto, recorren un mismo camino. Segovia entendida como final de trayecto, en cuanto a la adición como estrategia se refiere, parece más inteligible cuando la enfrentamos a su espejo.

Para concluir, señalar que por su aspecto (tosco y exagerado) el proyecto puede indu- 
cir a error como hasta ahora ha ocurrido. Las premisas establecidas en el encargo, el programa rígido y claro, y las pautas funcionales determinan un proyecto que en una mirada rápida puede aparentar lo que no es.

\section{Notas}

1. Proyecto catalogado en el Archivo Inza con el $\mathrm{n}^{\circ}$ 37: Fábrica de Embutidos para Félix Postigo Herranz. S.A ( $1^{\text {a }}$ fase) mayo 1963.

2. SMITHSON, Alison. "How to recognaise and read mat-building. Mainstream architecture as it has developed towards the mat-building", Architectural Design, septiembre 1974. Londres. p. 573590.

3. Hasta llegar al término acuñado por Smithson y mirando hacia atrás en el tiempo, ya se habian realizado una serie de edificios por parte sobre todo de miembros del Team X y otros arquitectos de la tercera generación como Candilis, Josic, Woods o Hertzberger. El antecedente de todos ellos había sido el Orfanato de Amsterdam (1955-60) de Aldo van Eyck, miembro también del Team X y primero en realizar un proyecto de este tipo. Casi en paralelo al Orfanato se construyen los Baños del Centro para la comunidad judía en Trenton (Nueva Jersey. 1954-59) de Louis Kahn, que desde el otro lado del Atlántico trabajaba en cuestiones similares.

4. Las propuestas del concurso se habian publicado en Arquitectura n ${ }^{\circ} 175$ (julio de 1956); el proyecto de ejecución en el no 188 (agosto de 1957) y la obra construida en el $n^{\circ} 198$ (junio de 1958) y en el $\mathrm{n}^{\circ} 200$ (agosto de 1958).

5. Louis Kahn fue el encargado de cerrar el congreso con una conferencia titulada: "Las nuevas fronteras de la arquitectura: C.I.A.M de Oterloo, 1959". Kahn, Louis. "I love beginnings" (Discurso pronunciado en el Congreso Internacional de Diseño, Aspen, Colorado). En: Architecture and Urbanisme (número dedicado a L. Kahn) 1975, p.278-286. Al final de su conferencia, cita a los Smithson y concluye: "Me gustaría terminar aquí, pero primero quiero mostrar mi aprecio por Aldo van Eyck". De este modo Kahn pasa el testigo generacional al Team $\mathrm{X}$ a través de algunos de sus miembros más destacados.

6. Obra que tendrá una influencia decisiva en uno de los caminos proyectuales que indagó Inza más adelante: la Casa de Somosaguas (1965).

7. Ver: "Orfanato en Ámsterdam de Aldo Van Eyck", p.18. En: "Panorama de la arquitectura de 1960", Arquitectura n ${ }^{\circ}$ 30, junio 1961. COAM, Madrid.

8. El encargo era de Alberto Martín-Artajo, antiguo colaborador con el que posteriormente firmo algunos anteproyectos. Este proyecto está catalogado en el Archivo Inza con el $\mathrm{n}^{\circ}$ 051: Proyecto de Chalet en Somosaguas, Madrid, octubre 1965.

9. "Arquitectura de marcado carácter expresionista, jugando tanto con los materiales (ladrillo) como con los elementos estructurales (vanos, aleros, cornisas, etc). Supone una de la aportaciones arquitectónicas más interesantes de esta segunda mitad del siglo XX en Segovia". Chaves Martín, Miguel Ángel. Catálogo-Guía de Arquitectura de Segovia. Segovia: Ed. Caja de Segovia, 1998.

10. "Una imagen en muy poco alejada del expresionismo alemán que a principios del siglo XX sacudió el panorama arquitectónico europeo. A la hora de escribir estas líneas tengo ante mis ojos algunas fotografias antiguas de la fábrica de productos químicos de Hans Poelzig en Luban, junto a Poznan (Polonia, 1911-12) o el Segundo Goetheanum de Rudolf Steiner en Dornach (Suiza, 1924-28)". Delgado Orusco, Eduar- do. "Curro Inza, Maestro de la forma compleja o la metáfora como deber". Anuario de la Universidad Internacional SEK $\mathrm{n}^{\circ}$ 7. 2001. Segovia. p. 87-92.

11. "Esta expresividad que cobra aquí el ladrillo hace que pudiésemos establecer cierta comparación con algunos ejemplos del expresionismo holandés. Pero únicamente sería válida a la luz. de la consideración específica del material". Arnuncio, Juan Carlos. "Fábrica de chorizos. Francisco de Inza y Heliodoro Dolls.1965”, p. 60 En: AA. VV. Arquitectura moderna en Asturias, Galicia y Castilla-León. Ortodoxia, Márgenes y Transgresiones. Valladolid: Ed. Celestino Garcia Braña, 1998.

12. Ver por ejemplo en el Archivo Inza los proyectos $\mathrm{n}^{\circ} 92$ (Proyecto de edificio industrial. Madrid. Agosto 1959) y n ${ }^{\circ} 54$ (Proyecto de ampliación de fábrica de hielo. Madrid, Septiembre 1960).

13. Desde 1963 hasta día de hoy Heliodoro Dols ha seguido viviendo en Zaragoza.

14. Ver fábricas y diagramas en la revista Arquitec tura ${ }^{\circ} 55$ julio $1963, \mathrm{n}^{\circ} 56$ septiembre $1963 \mathrm{y} \mathrm{n}^{\circ}$ 61 enero 1964 entre otros. Ver también en Arquitectura $\mathrm{n}^{\circ} 47$, noviembre 1962. Ignacio Álvarez Castelao, p.23 y p.48. Salto de Arenas de Cabrales y Silvon.

15. Arquitectura $\mathrm{n}^{\circ}$ 95, noviembre 1966. COAM. Madrid. p. 18-23.

16. Ver en el Archivo Inza los planos y memoria correspondientes al Anteproyecto de febrero de 1963 dentro del proyecto $\mathrm{n}^{\circ}$ 37: Proyecto de Fábrica de Embutidos para Félix Postigo Herranz. S.A ( $1^{\text {a }}$ fase) Mayo 1963.

17. Ver en el Archivo Inza los planos y memoria correspondientes al Proyecto de mayo de 1963 dentro del proyecto $\mathrm{n}^{\circ}$ 37: Proyecto de Fábrica de Embutidos para Félix Postigo Herranz. S.A. ( $1^{\mathrm{a}}$ fase).

18. Publicado en Arquitectura $\mathrm{n}^{\circ}$ 65, mayo 1964 COAM, Madrid. p.2 y Arquitectura ${ }^{\circ} 71$ noviembre 1964, COAM, Madrid. p.62.

19. Iglesia de Almendrales. Madrid. José María García de Paredes. Proyecto 1961 y ejecución 1964 Su nombre completo es: Iglesia parroquial Nuestra Señora de Fuencisla.

\section{Bibliografia}

Archivo Inza. Depositado en la Biblioteca de la ETSAM. 2013

Arnuncio, Juan Carlos 1998. Fábrica de chorizos. Francisco de Inza y Heliodoro Dolls.1965, p. 60 En: AA. VV. Arquitectura moderna en Asturias, Galicia y Castilla-León. Ortodoxia, Márgenes y Transgresiones. Valladolid: Ed. Celestino García Braña.

AA.VV. 1992. J.M. García de Paredes. Arquitecto (1924-1990). Madrid: Miguel Ángel Baldellou (coord.). Madrid: ed. COAM

Castro, Carmen 1971. Entrevista. Francisco de Inza. Fábrica de chorizos en Segovia. (Los Arquitectos critican sus propias obras). Arquitectura, 153 53-58.

Chaves Martín, Miguel Ángel. 1998. Catálogo-Guía de Arquitectura de Segovia. Segovia: Ed. Caja de Segovia.

Cortés, Juan Antonio.1999. Las visicitudes de una propuesta arquitectónica: de Torre Valentina a East Aglia. En: J.A. Coderch. Torre Valentina. Barcelona: Ediciones UPC, Publicado por l'Escola Técnica Superior d'Arquitectura del Vallés.

Delgado Orusco, Eduardo. 2001. Curro Inza, Maestro de la forma compleja o la metáfora como deber. Anuario de la Universidad Internacional SEK $\mathrm{n}^{\circ}$ 7:87-92

Fullaondo, Juan Daniel. 1973. Fenomenología en Carlos de Miguel. Conversación con Carlos de Miguel. Nueva Forma, 95.

Inza, Francisco 1966. La fábrica de embutidos de Segovia. Arquitectura, 95:18-23.

Kahn, Louis. 1975. I love beginnings (Discurso pro- 
nunciado en el Congreso Internacional de Diseño, Aspen, Colorado). En: Architecture and Urbanisme (número dedicado a L. Kahn): 278-286.

Rowe, Colin. 1978. Manierismo y arquitectura moderna y otros ensayos. Barcelona: Ed. Gustavo Gili. Ruiz Cabrero, Gabriel. 2001. El Moderno en España. Arquitectura 1948-2000. Sevilla: Tanais Ediciones.

Tena, Luis. 1999. Memoria de Curro Inza. Arquitectura, 318: 48-51.

Smithson, Alison.1974. How to recognaise and read mat-building. Mainstream architecture as it has developed towards the mat-building. Architectural Design, septiembre. Londres. 573- 590.

Verdasco, Ángel. 2013. La arquitectura de Curro Inza: una aproximación crítica y proyectual. Tesis doctoral. ETSAM. Madrid.

Verdasco, Ángel. 2016. El Archivo de Curro Inza. Madrid. Ed: Mairea Libros.

Fecha final recepción artículos: 24/04/2016

Fecha aceptación

20/06/2016

Artículo sometido a revisión por dos revisores independientes por el método doble ciego. 